\title{
Waste management in Mongolian hospitals
}

\author{
Walter Popp ${ }^{1}$, Altantuya Jigjidsuren², Ulambayar Badarch ${ }^{3}$, Tsogtbaatar Uyanga ${ }^{4}$, \\ Birgit Ross ${ }^{1}$, Khand Zorigt ${ }^{1}$, Jörg Spors ${ }^{5}$, Claude Bodart ${ }^{2}$ \\ 1. University Clinics of Essen, Essen, Germany \\ 2. Asian Development Bank, Ulaanbaatar, Mongolia \\ 3. Chingeltei District Hospital, Ulaanbaatar, Mongolia \\ 4. Second General Hospital, Ulaanbaatar, Mongolia \\ 5. Fire Brigade, Essen, Germany
}

doi: 10.3396/IJIC.v10i1.008.14

\begin{abstract}
An overview is given about waste handling in hospitals in Mongolia. Basically, handling of waste is regulated according to international standards. But in reality there are several problems, specially outside of the capital Ulaanbaatar. The situation is described, examples of problems are given and also some proposals are made how to improve the situation.
\end{abstract}

Keywords: Medical Waste Disposal, Waste Disposal facilities

\section{Introduction}

Mongolia is a very vast country between Russia and China with a small population of about 2.9 million people. Health care is provided by family doctors in Family health centres who are the first point of contact in the public healthcare system organised by the state. These family doctors, representing the primary level, are similar to soum (district) health centres in the countryside. The secondary level is represented by general hospitals in provinces and district hospitals in Ulaanbaatar city. Tertiary care hospitals are mostly located in Ulaanbaatar city, the capital of Mongolia with nearly half of population living there.

In 2010, a common German-Mongolian project started evaluating hospital hygiene in some pilot hospitals in Ulaanbaatar and also for the Emergency Service in Ulaanbaatar: Mongolian emergency service hospital Hygiene project (MeshHp) (www.meshhp.mn). ${ }^{1}$ During this ongoing project we had numerous chances to

\section{Corresponding author}

Walter Popp

University Clinics of Essen, Essen, Germany

email:walter.popp@uk-essen.de 
visit hospitals in Ulaanbaatar and also in different aimags (provinces) and soums and acquired a rather good overview about handling of waste in healthcare facilities.

\section{Regulation of waste handling in hospitals}

Mongolia has a good legal and regulatory foundation in terms of medical waste management. In 1998 after a turbulent transition from a centralised economy, the Government of Mongolia first issued a regulation on health care waste classification, collection, storage, transportation and disposal. This regulation was updated in 2002 by the joint ministerial order of the Ministry of Environment and Ministry of Health (Joint order No249/201, 2002). ${ }^{2}$ In 2009, a new "Strategy for Improving Healthcare Waste Management in Mongolia" for waste management was implemented, based on WHO recommendations, emphasizing the use of non-burning technologies. The action plan associated with this strategy included strategic improvement targets for medical waste management from 2009 to 2013 (Order No293, 2009). ${ }^{3}$ In the context of the new strategy, the Ministry of Health set up a centralized medical waste treatment facility in Ulaanbaatar which began its operations in 2010.

This was the first private and public partnership (PPP) initiative implemented in the health-care system. The government provided an initial investment to procure autoclaves for disinfection of disposals (waste) and an incinerator for burning biological waste. A private company was engaged in operational management of the centralized facility. At the same time, many small medical waste burners at city hospitals were eliminated to support the newly established centralized treatment facility.

Later in 2011 with the technical support of $\mathrm{WHO}$, the new strategy was reinforced by several orders that (i) regulates the financing aspect of medical waste treatment (Order No93, 2011), ${ }^{4}$ (ii) defines operational procedures and guidelines for collection, segregation, storage and transportation of the waste (Order No158, 2011), ${ }^{5}$ (iii) provides general technical requirements for a medical waste disposal facility at the province and soum level; requirements for bio-waste holes; list of required equipment for the health care disposal facility (Order No179, 2011), ${ }^{6}$ and (iv) defines general operational guidelines of the Central health care waste disposal facility (Order No380, 2011). ${ }^{7}$

Despite the absence of some aspects, such as the management of chemical, pharmaceutical and liquid medical waste, and the maintenance of waste treatment equipment, overall a sufficient legal framework exists to implement a comprehensive medical waste management system in Mongolia. However, the development of the administrative and reinforcement systems for medical waste received less support in the past and is today underdeveloped. There is no designated or appointed agency or institution available, which systematically collects medical waste data and evaluates medical waste indicators. Regular reports indicating potential weak points are not prepared and opportunities for improvement have been missed.

\section{Reality is different}

\section{"Element" company in Ulaanbaatar}

The centralized health care waste treatment facility is located outside of Ulaanbaatar at the Naren Enger Landfill area. The treatment facility land is owned by Ulaanbaatar City. The equipment was purchased by the Ministry of Health and provided to the licensed operator under a short-term PPP arrangement. There are several potential points of conflict, such as the duration of the contract, land ownership arrangements, and supervision of maintenance requirements. These uncertainties and insecurities are resulting in a problematic relationship between the private and the public partner.

The current PPP operator "Element" company collects on a routine basis medical waste from all public and private health care facilities in Ulaanbaatar city, and after autoclave disinfection disposes the waste using a land filling method. The facility consists of one autoclave unit for needles and sharps working at $134^{\circ} \mathrm{C}$ (capacity about $100-150 \mathrm{~kg} / \mathrm{h}$ depending on the waste density and treatment time, assumed $120 \mathrm{~kg} / \mathrm{h}$ ) and one incinerator which fail to meet any technical or environmental standards. It worked around $900^{\circ} \mathrm{C}$ for nearly one hour; ash is taken out by hand, sampled outside openly, and then transported to the landfill area. The incinerator can work only 


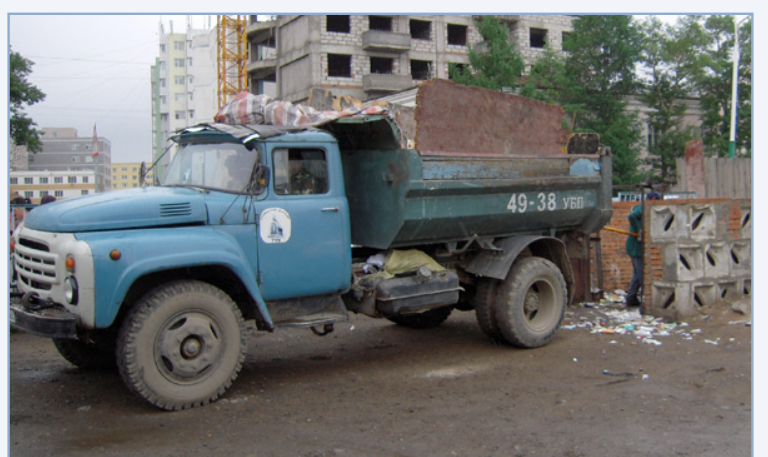

Figure 1. Typical picking up and transport of household waste from one big hospital in Ulaanbaatar

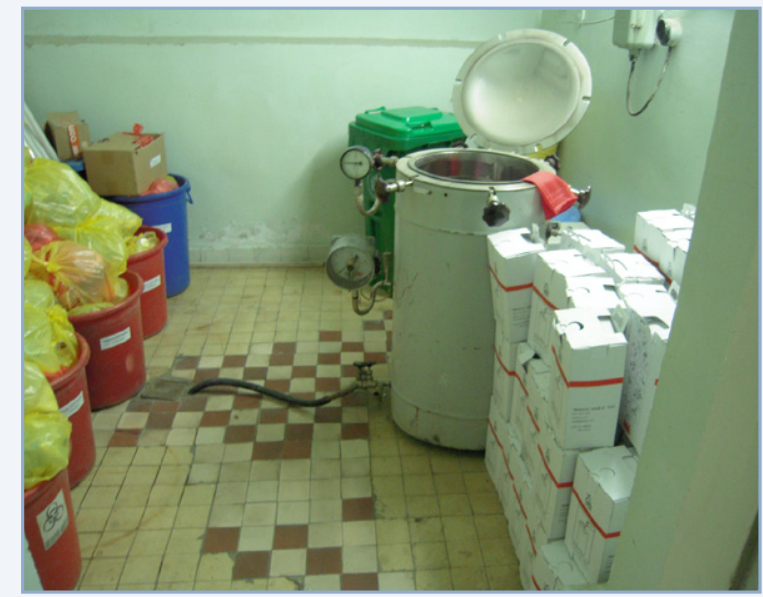

Figure 2. Typical waste sampling room in a hospital in Ulaanbaatar with steriliser for sharps, not working, but still kept for inspections

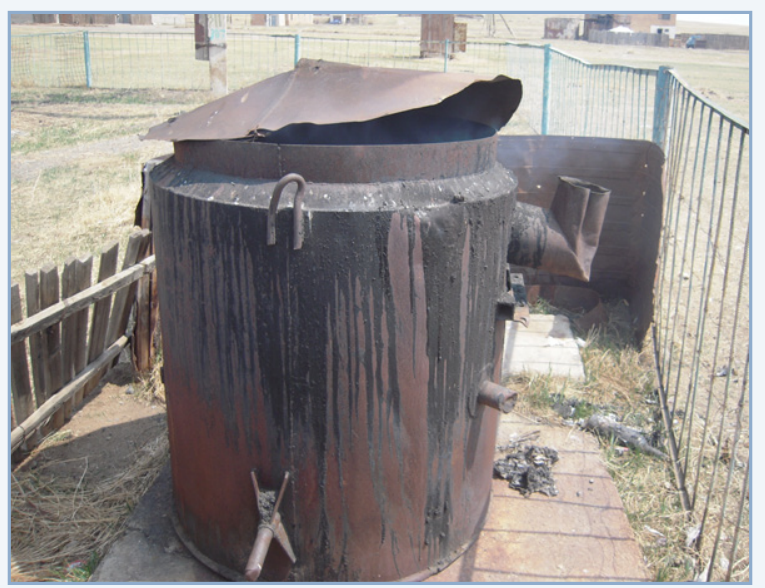

Figure 3. Typical self constructed waste incinerator in a soum hospital
2-3 hours maximum a day. There is no burning of normal waste; everything is going to be land filled. But needles and sharps are sterilised in autoclaves, after sterilisation they are shredded and taken to the landfill area. Biological waste is collected in the reusable yellow boxes for transportation, which later on are washed with a high pressure water stream and cleaned by hand. Only gloves were used by workers, not masks. The facility has no capacity for the storage and neutralisation of liquid or solid hazardous waste.

\section{Waste management at the health care facilities}

During project implementation we visited several hospitals and health centres in Ulaanbaatar and in several provinces. Everywhere the waste is collected in different fractions on the wards. In Ulaanbaatar, normal waste is picked up by municipal waste sampling lorries in a very simple way and taken to the landfill area (Figure 1). The other 2 types of waste (sharps and biological waste) is collected up to three times a week by "Element" cars and taken to the centralized treatment facility. Most of the hospitals do not have money in their budgets to buy enough safety boxes; therefore, they often use self-constructed paper boxes.

Handling of "infectious waste" is rather well organized in Ulaanbaatar by the "Element" company. Outside of Ulaanbaatar, it seems completely different. In provinces, the situation very much depends on how managers understand the issue and how they implement the ministerial orders. Most of the hospitals we visited do not sterilise the sharps waste (Figure 2). The reasons are: (i) sterilisers are too old and not functioning properly, (ii) the capacity of sterilisers is not sufficient to disinfect waste and mostly used only for sterilisation of in-house medical instruments and other supplies, (iii) sterilisers are not working because they were not installed properly or, very often, there is no one who is capable of doing maintenance or repair of sterilisers, and (iv) hospitals have almost no budget allocated for maintenance of medical equipment, including sterilisers. Province hospitals very often use self-constructed incinerators or ovens (Figure 3). What was common is that the ashes from burning are usually thrown in holes on the hospital grounds.

Here are some examples of how differently province health care facilities are handling medical waste: 
- One province hospital performs autoclave disinfection of used needles, but recaps the needles (Figure 4).

- In some provinces only sharps are burned in incinerators while other waste, including infectious materials and biological tissue, were not burned and thrown away without sterilisation in holes near the hospital.

- We could also see that all waste was subsequently thrown together and burned in the open air.

- We also visited a soum health centre, which had one oven for household waste and one for infectious waste, but needles where thrown in a hole outside without burning.

- In most of the province hospitals and soum health centres the infectious waste, like placentas and other pathologic waste, is thrown in holes on the hospital grounds (Figure 5), which are closed sometimes, but very often open and with free access to wild dogs and birds.

- One province hospital had outsourced the hospital waste management to a private company. As far as we could see the private company tried to work with higher safety standards, e.g. staff was wearing protective clothing. The used needles in that hospital were sterilised but burned at the public landfill area. They are delivered in safety boxes (made from paper); the responsible worker at the land fill area decided on his own to burn them in open holes. This is reducing the waste amount so that he is not forced to dig a new hole every day (Figure 6).

\section{Waste handling in Fifth health Sector Development Project of Asian Development Bank (ADB)}

The Fifth Health Sector Development Project (20132018) funded by Asian Development Bank (ADB) will address safe blood bank, hospital hygiene and waste management in the healthcare system. ${ }^{8}$ The project will support the Government of Mongolia in implementing its strategy on medical waste management by (i) upgrading and expanding the central medical waste facility in Ulaanbaatar, to meet international standards, (ii) providing interim hazardous waste storage places in Darkhan and Erdenet as well as one central hazardous waste reception and recycling facility in Ulaanbaatar, (iii) providing one long-term storage place in Ulaanbaatar for hazardous waste; (iv) constructing one

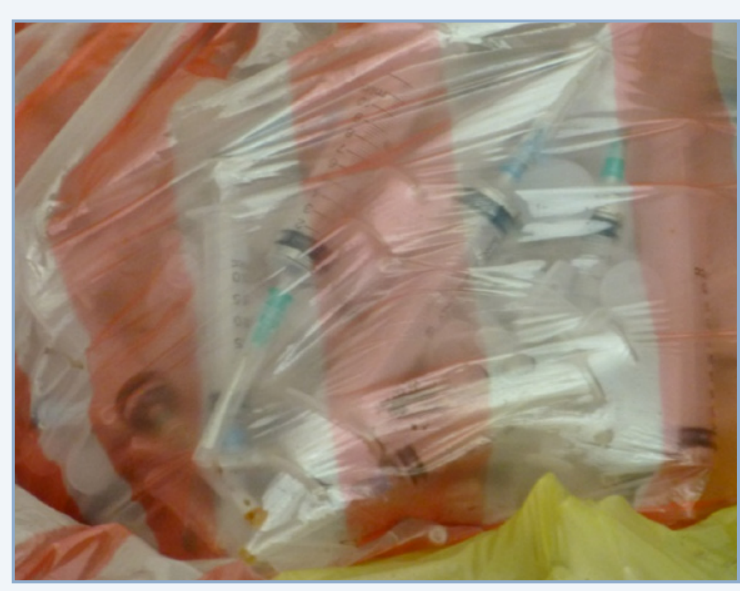

Figure 4. Needles are sterilised, but all are recapped.

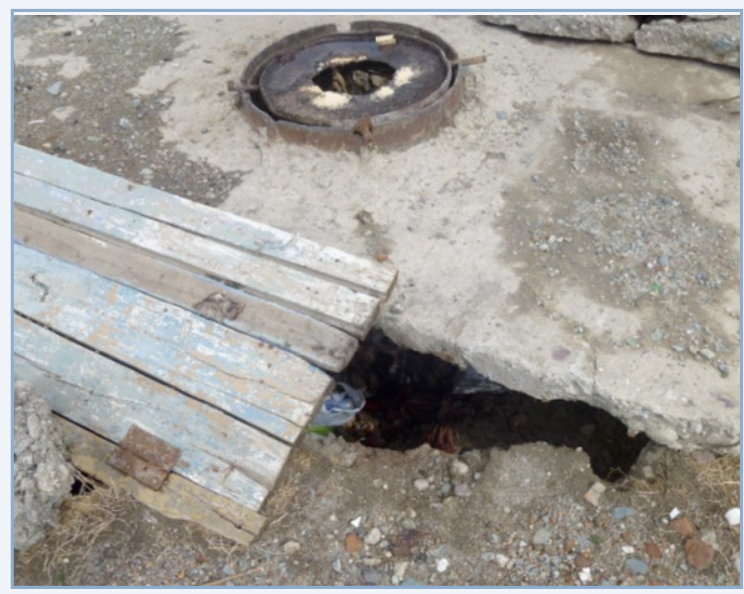

Figure 5. Typical open hole for biological waste.

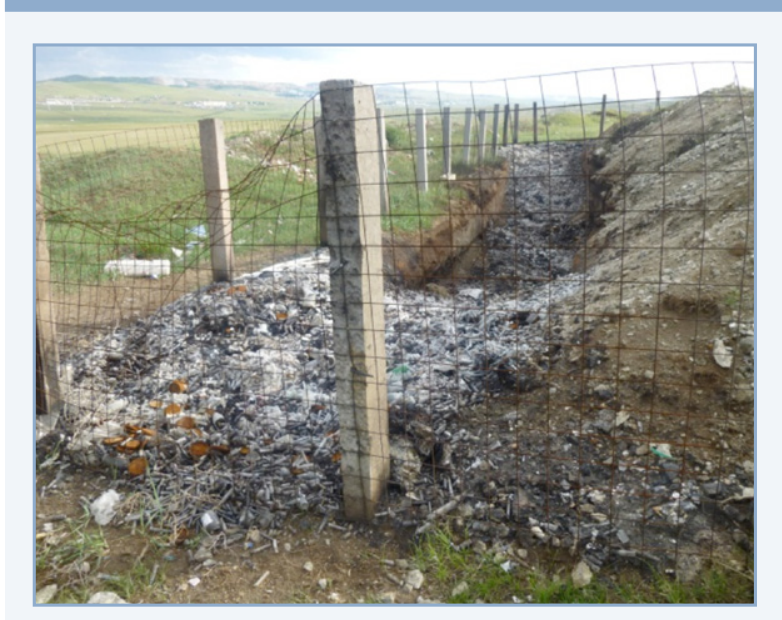

Figure 6. Needles in safety boxes are burned on decision of responsible worker at the landfill area of an aimag city. 
facility in Ulaanbaatar for the reprocessing of reusable sharps containers and for the recycling of plastic waste; and (vii) providing small medical waste equipment to 21 hospitals at the aimag and central level to improve their medical waste management systems. All project facilities will meet international requirements, and are standardized under $\mathrm{MOH}$ Order $179 .{ }^{6}$ The Federal Ministry of Health of Germany and WHO will be a partner with $\mathrm{ADB}$ in implementing this project.

\section{Discussion}

Basically, handling of waste is regulated in Mongolia according to international standards. However the reality is different in many hospitals, especially outside of the capital Ulaanbaatar:

- Sterilisation of sharps is not routinely done.

- Incineration is very often done, however also throwing the different types of waste together.

- The handling of pathological waste is not sufficient.

Perhaps it would be appropriate to revisit $\mathrm{MoH}$ policies on waste management, following WHO guidelines, ${ }^{9}$ given the limited resources available to hospitals. The use of autoclaves for waste disinfection might not be fully justified since Mongolia has sufficient land to establish protected landfills and the amount of waste is generally small in aimag and soum hospitals. There are no children or drug users searching for needles in Mongolia, making landfill acceptable. It is ironic that several visited hospitals use modern autoclaves to sterilise waste but do not have appropriate autoclaves in their central sterilisation departments.

So the way many hospitals go - burning sharps and sending them and other waste to landfill areas - might be an acceptable solution. The environmental impact of these small incinerators is very small, especially in comparison to other air pollution sources like old cars, lorries, ger heating, power stations and so on. Also, this effort must be seen in comparison to the size of the country.

Of course, some problems have to be solved:

- Landfill areas must be better protected, e.g. with fences.

- Pathological waste (e.g. placenta) cannot be thrown any longer into open holes, they must be incinerated or collected in central places or - at least - thrown and collected in holes which can firmly be closed.

\section{Funding}

MeshHp project is sponsored by Federal Republic of Germany.

\section{References}

1. Popp W, Badarch U, Tsevegjav A, et al. Hospital hygiene in Mongolia and the MeshHp project. Int I Infect Control 2013; 9(2). http://dx.doi.org/10.3396/IJIC.v9i2.018.13

2. Joint ministerial order of the Ministry of Environment and Ministry of Health No249/201, 2002.

3. Order of the Minister of Health No293, 2009. "Strategy for Improving Healthcare Waste Management in Mongolia"

4. Order of the Minister of Health No93, 2011. "Regulation on the financing aspect of the medical waste management".

5. Order of the Minister of Health No158, 2011. "Operational procedures and guidelines for collection, segregation, storage and transportation of the waste".

6. Order of the Minister of Health No179, 2011. "General technical requirements for medical waste disposal facility at the province and soum level; requirements for bio-waste holes; list of required equipment for the health care disposal facility".

7. Order of the Minister of Health No380, 2011. "General operational guidelines of the Central health care waste disposal facility".

8. The Fifth Health sector Development Project, Initial Environmental Examination, ADB, 2012

9. WHO: Safe management of wastes from health-care activities. Second edition. 2013 